\title{
DESLOCAMENTOS ARTE-EDUCATIVOS NA TRANSAMAZÔNICA- XINGU COMO EXPERIÊNCIAS DO SENSÍVEL EM DIREÇÃO A UMA OUTRA PARTILHA DO COMUM
}

Art-educational displacements in the Transamazônica-Xingu area as experiences of the sensitive shared toward a new sharing of the common

Desplazamientos en arte educación en la Transamazónica-Xingu como experiencias de lo sensible hacia otro compartir de lo común

$>$ Leonardo Zenha [Universidade Federal do Pará, Brasil] ${ }^{*}$

Raquel Lopes [Universidade Federal do Pará, Brasil] *

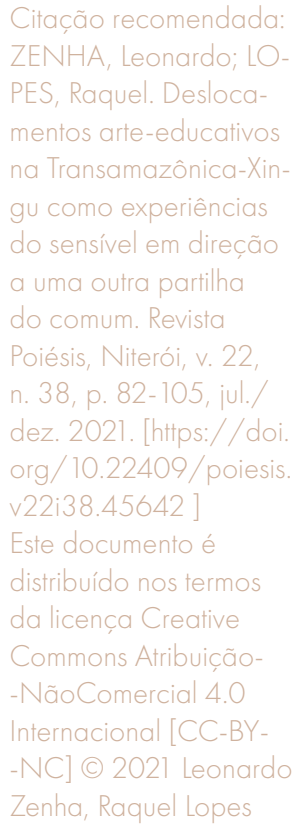

\section{RESUMO}

O objetivo do trabalho é compartilhar experiências no campo da arte e da educação, demonstrando atos de deslocamento como experiências de partilha do sensivel. Pela realização de ações coletivas com estudantes de graduação e da educação básica, a partir de dispositivos visuais como a fotografia, o vídeo e a instalação, procurou-se materializar possibilidades e inquietações no campo da arte-política, focando temas do cotidiano das populações locais, trazendo a lume pontos de tensão e ruptura na perspectiva da construção de um novo comum a ser partilhado a partir dos olhares dos sujeitos que vivem nesse território.

PALAVRAS-CHAVE Amazônia, arte, sensível partilhado, educação

\section{ABSTRACT}

The aim of this work is to share experiences in the field of art and education, evidencing acts of displacement as experiences of sharing of the sensitive. From performing collective actions with undergraduate and high school students, using imaging devices like photography, video and installations. We seek to materialize possibilities and concerns in the field of political art, focusing on themes of the daily lives of local populations, bringing highlights points of tension and rupture, in the perspective of building a new common to be shared from the perspective of the subjects who live in that territory. KEYWORDS Amazônia, art, sensible shared, education

*Leonardo Zenha é Doutor em Políticas Públicas e Formação Humana pela UERJ e professor na Universidade Federal do Pará. E-mail: leozenha@gmail.com
**Raquel Lopes é Doutora em Ciências Sociais/Antropologia pela Universidade Federal do Pará, onde também leciona. E-mail: ralopes@ufpa.br

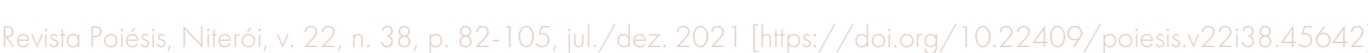


(Submetido: 30/8/2020;

Aceito: $7 / 1 / 2021$;

Publicado: $7 / 7 / 2021$ )

\section{RESUMEN}

El propósito de este ensayo es compartir experiencias en el campo del arte y de la educación, demonstrando actos de desplazamiento como experiencias para compartir de lo sensible. Mediante la realización de acciones colectivas con estudiantes de graduación y de la enseñanza básica, a partir de dispositivos visuales como la fotografía, el vídeo y la instalación, se ha buscado materializar posibilidades e inquietudes en el campo del arte político, centrándose en temas del cotidiano de las poblaciones locales, exponiendo puntos de tensión y fracturas en la perspectiva de la construcción de un nuevo común a ser compartido a partir de la mirada de los sujetos que viven en ese territorio.

PALABRAS CLAVE Amazonia, arte, compartir de lo sensible, educación 
INTRODUÇÃO: "E DE NADA VALERIA ACONTECER DE EU SER GENTE. E SER GENTE É OUTRA ALEGRIA. DIFERENTE DAS ESTRELAS...' que façam parte de uma justa "partilha do sensível", condenando-as a um comum empobrecido, opacificado, desumanizado.
Você não precisa de artistas? Então fecha os olhos, mora no breu. Esquece o que a arte te deu, finge que não te deu nada. Nenhum som, nenhuma cor, nenhuma flor na sua blusa. Nem Van Gogh, nem Tom Jobim, nem Gonzaga, nem Diadorim [...]. Você vai rimar com números. Vai dormir com raiva, e acordar sem sonhos, sem nada. E esse vazio no seu peito não tem refrão para dar jeito, não tem balé para bailar [...] Você não precisa de artistas? Então nos perca de vista. Nos deixe de fora desse seu mundo perverso, sem graça, sem alma.

Os excertos acima apontam, cada um a seu modo, a imprescindibilidade da dimensão artística na constituição do humano em nós. Neste texto, pretendemos compartilhar duas experiências arte-educativas que evidenciam essa proposição e nos desafiam a pensá-la em sua radicalidade, para além de certas obviedades ou lugares-comuns a que fomos acostumados por uma tradição que nos levou ao afastamento entre "fazer e sentir", separando-nos em blocos distintos: os que pertencem ao mundo da vida 'prática' [e trabalham] e os que pertencem ao mundo etéreo [e apenas sentem]. Pretendemos, também, questionar pressupostos dessa tradição que afasta a arte da política, problematizando o quão nociva e desumanizante é essa separação, pelo fato de negar o direito ao prazer artístico a grandes parcelas da população, ao impedir
Num momento tão delicado no mundo, trazemos esse relato de experiências do sensível vivenciadas no interior da Amazônia paraense, pelas ruas da Transamazônica e pelos rios do Rio xingu, provocando o pensamen-

to e o saber sobre arte, política Zélia Duncan e essas formas de resistências construídas, reelaboradas, cocriadas e compartilhadas por pessoas comuns nos mais longínquos lugares. Acreditamos em sua importância e tentamos refletir sobre essa temática da arte-política, buscando vivenciá-la como forma de partilha do sensível [RANCIÈRE, 2005], partilhando sua potência como diálogo e produção de humanidade no cotidiano de vida e resistência dos povos desse lugar, a partir das experiências do fazer coletivo. Queremos pensar a arte [assim como a política] como forma de produção de conhecimento socialmente situado, mas dialeticamente móvel, volante, diaspórico: florestas, rios, praças e ruas em movimento, deslocados.

As experiências aqui trazidas emergiram nesse encontro entre arte e política, advindas de processos educativos que foram ganhando cor, forma, criação 
e cocriação [CORDEIRO; LOPES, 2020; SANTOS; WEBER, 2015] com os estudantes e outros sujeitos do campo, da cidade e dos rios no interior da Amazônia Paraense. Esses "deslocamentos" de arte e política foram sendo construídos em processos de formação, seja no curso de Pedagogia, ao nível da educação superior, seja no curso do Magistério das Reservas Extrativistas, ao nível da educação básica; seja na cidade [Uruará e Altamira], seja nas comunidades ribeirinhas [Resex Rio Iriri].

Esse é o convite: partilhar, trocar, aprender, desaprender. Sentir a arte, a educação e a política como maneiras de fazer, com mais abertura ao devir, àquele vir a ser ainda em embrião, incerto mas promissor; com menos apego ao passado como porto seguro, mas aprendido como lição de experiência/saber que impulsiona passos novos em deslocamento, tanto do corpo físico que sai da sala de aula, dos muros seguros da escola, e vai para as ruas, quanto do corpo-pensamento que se reinventa na contradição para construir um novo comum e partilhá-lo, com mais beleza, mais alegria.

\section{DESLOCAR-SE: PENSAMENTO, EDUCAÇÃO,} ARTE E POLITICA EM MOVIMENTO

Aqui estabeleceremos algumas pontes de diálogo entre referências que nos ajudam a deslocar o pensamento sobre as temáticas tratadas, especialmente a relação entre o fazer artístico e o fazer político, na perspectiva da elaboração de uma nova partilha do comum. Considerando o caráter histórico e, portanto, passível de mudanças das disposições mentais pelas quais se formaram as concepções que sustentam nossas ações, tratamos a educação em sua transversalidade estrutural e estruturante de todo esse conjunto de percepções e hábitos mentais, móvel também de um comum em devir, a ser partilhado com base em novos parâmetros.

Começamos com Jacques Rancière [RANCIĖRE, 2005; 2012], particularmente no que diz respeito às proposições visando a uma nova "partilha do sensível" e aos desafios dos "paradoxos da arte-política". Nessa mesma direção, dialogamos também com as propostas de Campbell [2015], que traz várias experiências de grupos e coletivos com "intervenções urbanas, arte pública, arte participativa, arte colaborativa, arte relacional, arte contextual, situações..." [CAMPBELL, 2015, p. 20]. Essas duas principais referências se aproximam bastante, tanto entre si quanto relativamente aos nossos propósitos neste trabalho: evidenciar possibilidades de subversão na produção artística e na sua publicização, no seu processo de se dar a ver, de se tornar comum, por meio de uma rede de afetos que nos mobiliza, embora não nos dê garantias, pois como nos lembra Rancière: 
A vontade de repolitizar a arte manifesta-se assim em estratégias e práticas muito diversas. Essa diversidade não traduz apenas a variedade dos meios escolhidos para atingir o mesmo fim. Reflete uma incerteza mais fundamental sobre o fim em vista e sobre a própria configuração do terreno, sobre a que é a política e sobre o que a arte faz. Contudo, essas práticas divergentes têm um ponto em comum: geralmente consideram ponto pacífico certo modelo de eficácia: a arte é considerada política porque mostra os estigmas da dominação, porque ridiculariza os ícones reinantes ou porque sai dos seus lugares próprios para transformar-se em prática social [RANCIÈRE, 2012, p. 52]

Nessa perspectiva, as experiências aqui relatadas podem ser vistas numa direção dupla: como ato de vontade inscrito em uma ordem subjetiva de desejo/busca pela transcendência do fazer artístico qque implica o encanto pela beleza, a atratividade plástica exercida pela superfície física dos arranjos, assim como a pulsão do inédito e seu poder de sedução]; mas também como ato político inscrito na ordem do sensível comum que, ao ser partilhado, mobiliza e acende o desejo nos outros sujeitos envolvidos, engendrando uma ambiência coletiva de ação-criação coletiva.

Assim, essas experiências podem ser inicialmente atribuídas a uma autoria de sujeitos singulares, que as conceberam num dado momento como possibilidade/virtualidade [pensaram, escreveram, propuseram], mas só se atualizaram na materialidade histórica porque se tornaram coletivas e foram legitimadas e validadas por sujeitos coletivos que, como tal, se colocaram na cena pública e as assumiram como ato político, transgredindo fronteiras do possível da arte, desenhando marcas novas no improvável da política; enfim, recuperando de forma criativa os elos entre o fazer artístico e o fazer político naquele sentido lato e plural; movidos pelo desejo de atuar conjugando esses atos em uma performance que retoma a "gênese estética" que arte e política compartem. Campbell nos lembra que Rancière identificou a existência dessa gênese:
Escreve Jacques Rancière que há uma gênese estética que a arte compartilha com a política: ambas intervêm na partilha que fazemos do nosso mundo sensível. Arte e política são maneiras de se recriar as "propriedades do espaço" e os "possíveis do tempo", as condições históricas a partir das quais dividimos e percebemos o que é ruído e o que é palavra, o que é visível e o que é invisivel, os que fazem parte da cena ou dela estão excluídos. [CAMPBELL, 2015, p. 28]

\section{Revista Poiésis, Niterói, v. 22, n. 38, p. 82-105, jul./dez. 2021 [hitps://doi.org/10.22409/poiesis.v22i38.45642]}

As experiências aqui tratadas foram tecidas nas malhas do cotidiano, como maneiras de fazer cujo ponto de partida e de entrelaçamento se localiza nas práticas sociais no contexto do cotidiano [CERTEAU, 2009; ALVES, 2003, 2008], a exemplo das aulas, da coleta da castanha, da produção de farinha, da pesca; além de eventos ou episódios de intervenções como aqueles levadas a cabo por

\section{6}


artistas como Brígida Campbell, Paulo Nazareth e Éder Oliveira ${ }^{2}$. Esse mergulho na experiência e as reflexões daí decorrentes nos convidam a pensar os fazeres no dia a dia e suas possibilidades potencializadas pelas intervenções no campo da arte e da educação, tentando reaproximar o chão do cotidiano do fazer artístico e do fazer político, percepções muitas vezes negadas, mas que podem ser potencializadas pelo sensível: aprendizado de um novo sensivel, desencadeando várias outras mudanças nesse aparente "caos".

Nessa perspectiva, a arte deixa de ser uma mera atividade de entretenimento e torna-se forma de conhecimento, considerada como prática que vai muito além de pinturas elaboradas sem uma finalidade estabelecida. Ela tem um espaço fundamental na sociedade, tornando-se visível em diversas formas e linguagens: dança, música, teatro, pintura; o fazer artístico ganha, assim, novos espaços para além de museus e galerias, ocupando também ruas, praças, bares e periferias. Dessa forma, a arte, como área de conhecimento, seja na educação básica ou na superior, possibilita o desenvolvimento da criatividade e a sensibilidade humana, expandindo-se para abranger as manifestações culturais e políticas.

Para Campbell [2015], obras de arte realizadas no espaço público dão ênfase ao lugar, incorporando- o em todas as suas dimensões - físicas, sociais, culturais, ambientais. Praças, ruas, túneis, prédios, parques são espaços onde a arte se faz presente, embora muitas vezes fique imperceptível aos olhos da sociedade, devido à correria do cotidiano. Ao adotarem esses espaços, os artistas se aproximam do mundo real e diminuem a distância que se criou 
entre a vida prática e a prática artística; a cidade vai deixando de ser apenas estrutura física e passa ser um lugar de fluxo, criatividade, interatividade. Visto que a arte é algo imprescindível ao sujeito, ela se manifesta em resposta aos desafios do mundo, seja com um caráter de criação ou de 'consumo'/fruição. ditos, envolvendo os sujeitos e as práticas nesses processos de deslocamentos individuais e coletivos, apostando em suas diversas reverberações.

DESLOCAMENTOS 1 - [DES] CAMINHOS DA ARTE EM EDUCAÇÃO COM PROFESSORES EM FORMAÇÃO NA TRANSAMAZÔNICA [URUARÁ/PARÁ]

Em atividades da disciplina Arte e educação, ministrada com estudantes do Curso de Pedagogia pelo PARFOR ${ }^{3}$ /UFPA, no município de Uruará, na Transamazô-
As práticas artísticas que são expostas em muros de diversas cidades trazem consigo reflexões que, como bem aponta a autora acima mencionada, podem não ser identificadas de imediato frente à dimensão do que nos cerca, por estarem em um ambiente inusitado, podendo haver uma perda nesse potencial reflexivo diante dos problemas sociais que elas tentaram expressar. Esse é um risco que não pode invalidar as tentativas, pois as práticas artísticas carregam consigo uma expressão forte de cada cultura em que se inserem, provocando influências sobre o que elas pretendem expressar, criar e cocriar.

Trazemos a seguir alguns caminhos trilhados como processos experimentais do pensar a arte, a política e a educação nessa interação com espaços inau- nica, estabelecemos como objetivos potencializar reflexões acerca dos saberes teóricos e práticos no campo da arte e da educação, por meio de estudos, observações, experimentações e intervenções na cidade. Na turma, havia uma média de 24 estudantes, e a disciplina ocorreu em uma semana inteira, nos períodos da manhã e tarde. Em tão curto espaço de tempo e com tantas possibilidades, optamos pelas artes visuais e das intervenções.

Optamos por autores que trabalham o cotidiano e as intervenções artísticas, refletindo os limites e possibilidades da escola, do nosso fazer em educação visando maneiras de subverter a lógica vigente, pois acreditamos na proposição de Rancière quando diz que "As práticas artísticas são "maneiras de fazer" que 
intervêm na distribuição geral das maneiras de fazer e nas suas relações com maneiras de ser e formas de visibilidade." [RANCIÈRE, 2012, p. 17]. Essa proposta inicial, de certa forma, parte de um pensamento/fazer individual do professor, mas precisa de uma cumplicidade, uma adesão, um 'cimento' coletivo - que acontece em alguns momentos e, em outros, não.

Quando pensadas com base apenas em uma racionalidade técnico-instrumental ou colocadas de forma unilateral, essas propostas mais 'desviantes' têm grande probabilidade de não acontecerem ou de serem somente uma burocracia para cumprir um protocolo pedagógico; para se efetivarem como práticas artísticas significativas, precisam ter sua dimensão afetiva explorada, precisam tocar as pessoas. Por isso dizemos que saem do campo puramente racional para se alojarem e crescerem no campo do intuitivo e das "partilhas do sensível". Assim, ao lado de reflexões, experiências sensoriais, apreciação de videodocumentários, leitura

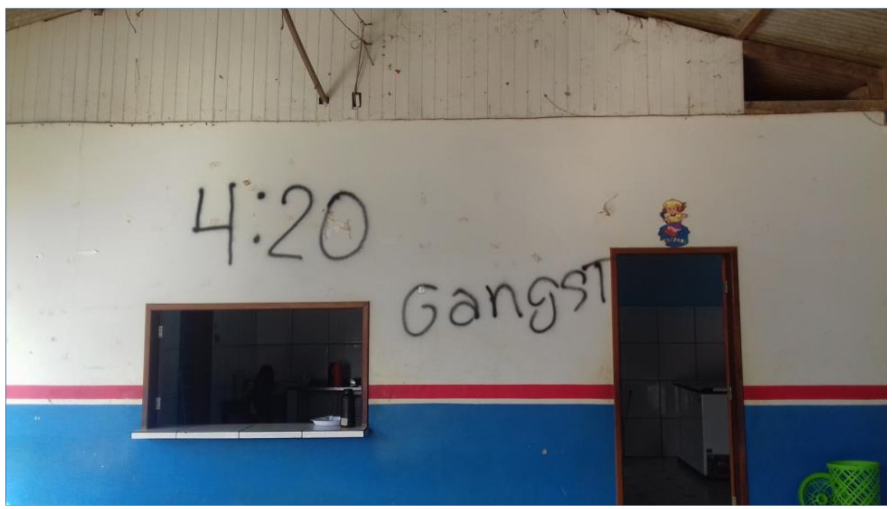

de textos, debates mais conceituais, realizamos experiências do olhar e saídas/deslocamentos da sala de aula para diferentes espaços da cidade.

Toda essa sequência "didática" vivenciada teve como foco pensar outros modelos de arte ou de arte-educação para além do conhecido ou do usualmente praticado pelas escolas e seus currículos. Como já foi dito, esses deslocamentos também tiveram que ocorrer no método de pensar/fazer, repensando o campo da arte e educação a partir de elementos da posição dos sujeitos frente a seu território. Quando os estudantes foram provocados pelos textos, debates, documentários e o papel da arte ou a situação de cada um ou de todos nesse processo, foram surgindo outros olhares sobre a cidade, a rua e o território. Nesse "flanar" pela cidade com os celulares e máquinas fotográficas, era possível perceber um certo grau de apreensão dos sentidos e, ao mesmo tempo, a possibilidade de explorar espaços e lugares sob o ângulo da arte da imagem.

Fig. 1 - Sequência de fotos Flanar pela cidade. [Fonte: Registros dos estudantes, 2017]

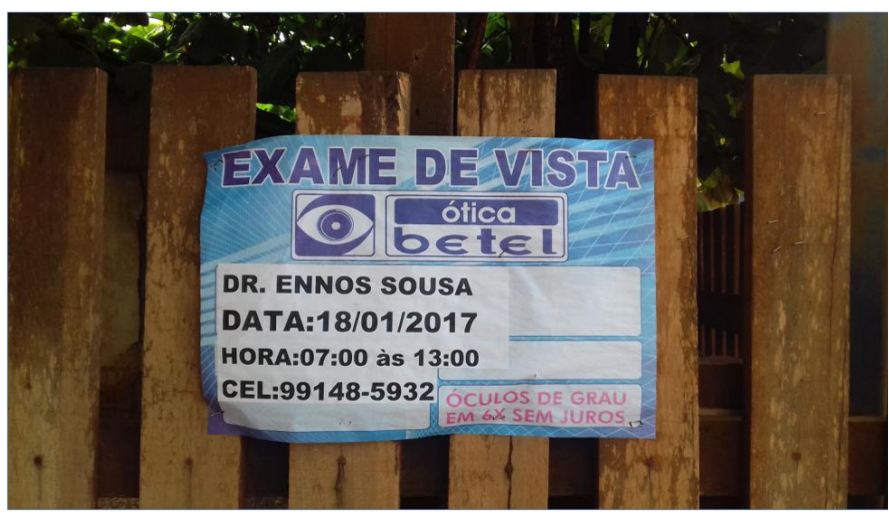




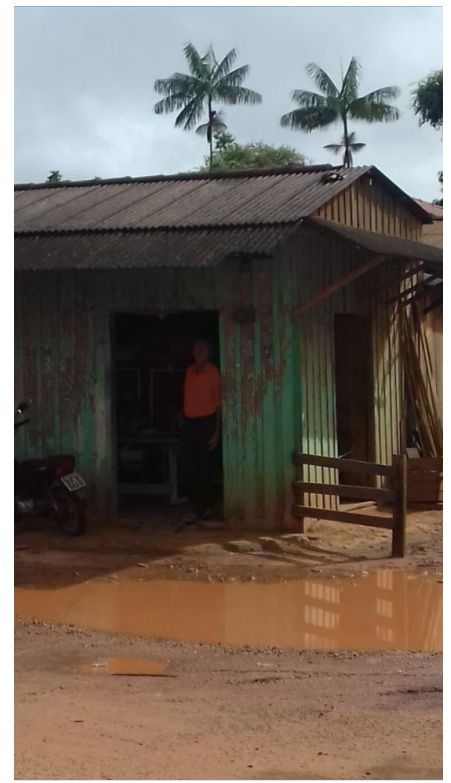

Fig. 2 - Sequência Flanar pela cidade [Fonte: Registros dos estudantes, 2017]
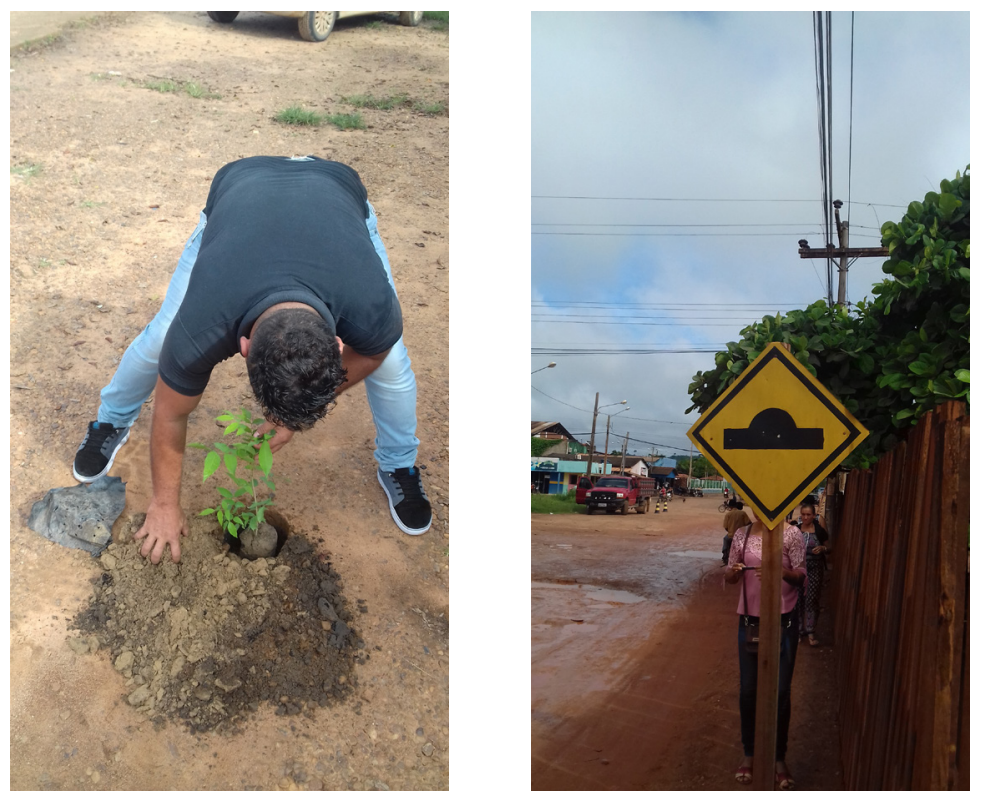

Fig. 3 - Sequência Flanar pela cidade [Fonte: Registros dos estudantes, 2017]
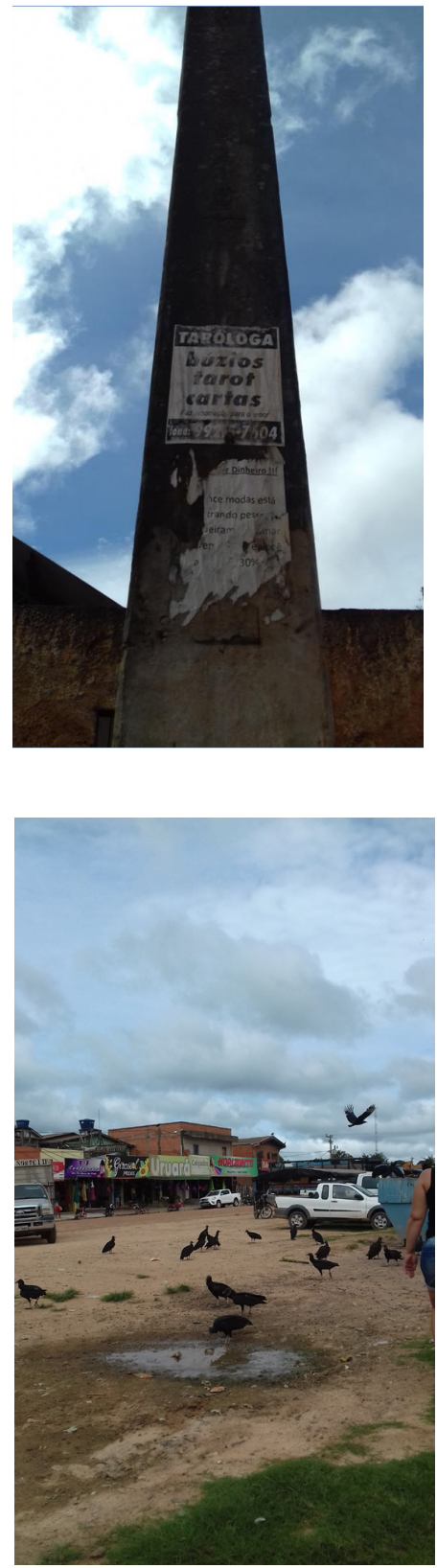
Outro ponto chave dessa experiência foram os elementos constantes nessa paisagem física e imagética. Em uma cidade construída ou cortada pela ditadura, como ocorreu ao longo da Transamazônica, suas contradições e fragilidades, o descaso com a saúde, a educação e até mesmo a forma da relação urbano/campo, na qual esses sujeitos foram socializados, se fazem presentes afetando seus modos de vida, as lutas diárias por sobrevivência e aqui, em específico, ganha destaque a luta pela formação na graduação em uma universidade pública.

Nessa construção de dispositivos [ARDOINO, 1998] e seus deslocamentos, refletindo sobre o papel da arte, o contexto, a educação para além da sala de aula e as possíveis formas de intervenção: instalações, exposições, murais, recitais, saraus e outras práticas/formas subversivas, foram surgindo discussões sobre o lugar e a participação de cada sujeito nesses espaços, com seus possíveis desconfortos e incômodos. Essa tomada de consciência da inseparabilidade entre arte e política tem muito mais a ver com uma percepção do sensivel, uma consciência corporal, do que com uma decisão racional, pois a percepção de si no coletivo leva a uma percepção do outro como sujeito e não mais como objeto.

Algumas fotografias foram projetadas em tamanhos maiores, foram impressas e colocadas em circulação novamente. Esse processo de manipulação das imagens no momento da sua captação e, depois, quando foram impressas, causou também novos deslocamentos, provocando olhares diferentes entre os estudantes.

Depois de algumas discussões e de análises das imagens, decidimos por uma intervenção na cidade com as fotografias [algo ainda inusitado e pouco comum], a serem colocadas nas praças por um mapeamento de possíveis espaços para a instalação de placas, com aproveitamento de madeiras encontradas nas caminhadas, sugestão de um grupo de estudantes.

Nesse processo de deslocamentos e intervenções pela cidade, foram se formando novas percepções dos sujeitos envolvidos. Convivendo com falta de estrutura, de suporte em saúde, educação e lazer, sem espaços como teatro, cinema ou museu, as pessoas podem ser sensibilizadas e começar a pensar provocações no campo da arte e da política; a experiência acima relatada evidencia que é possível, mesmo em condições adversas e pouco favoráveis em termos materiais, fomentar a construção de um novo comum a ser partilhado, proporcionado por reverberações em potencial de outras perspectivas no campo da arte e da educação. 

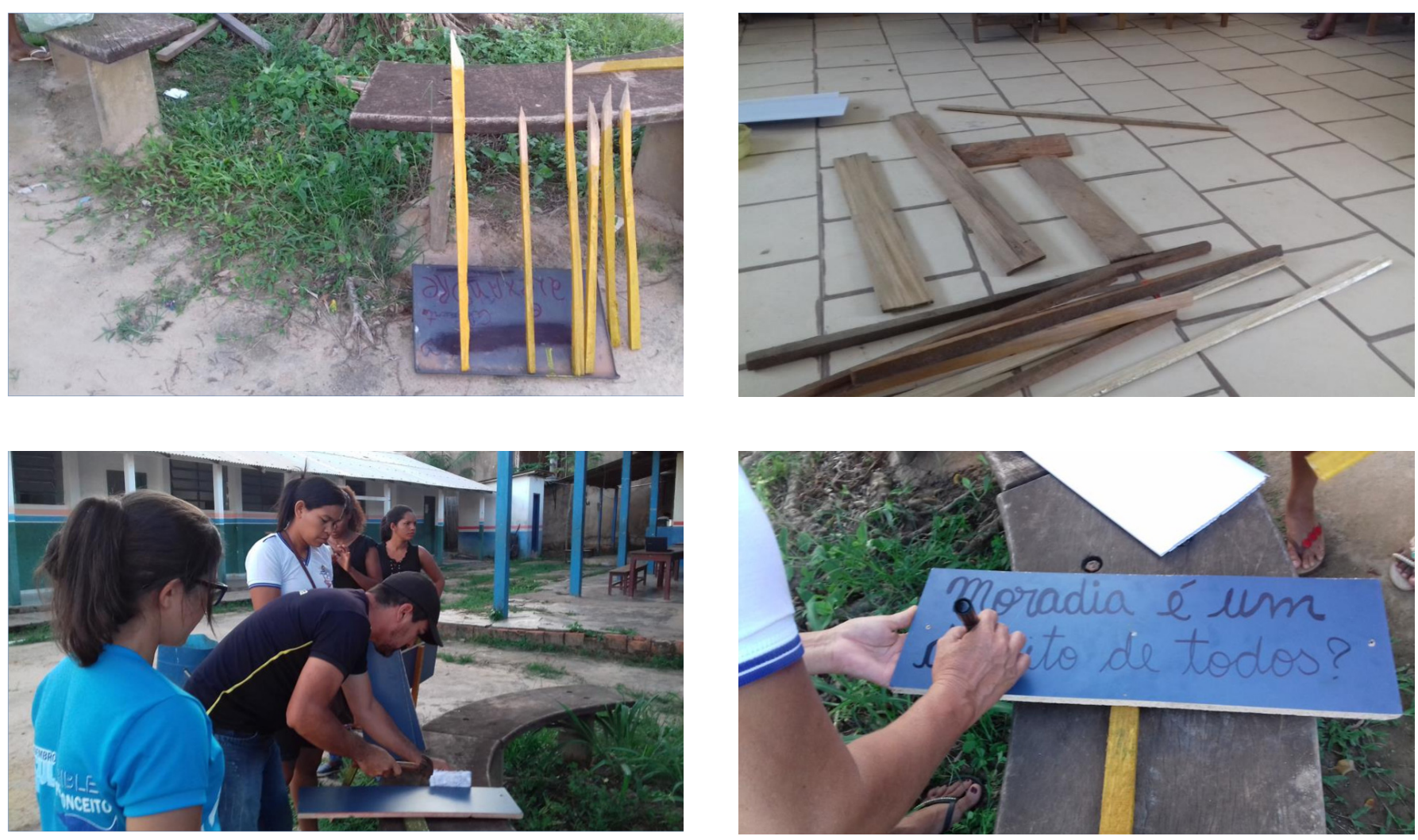

Fig. 4 - Sequência Preparação da intervenção. [Fonte: Registros dos estudantes, 2017]

92 

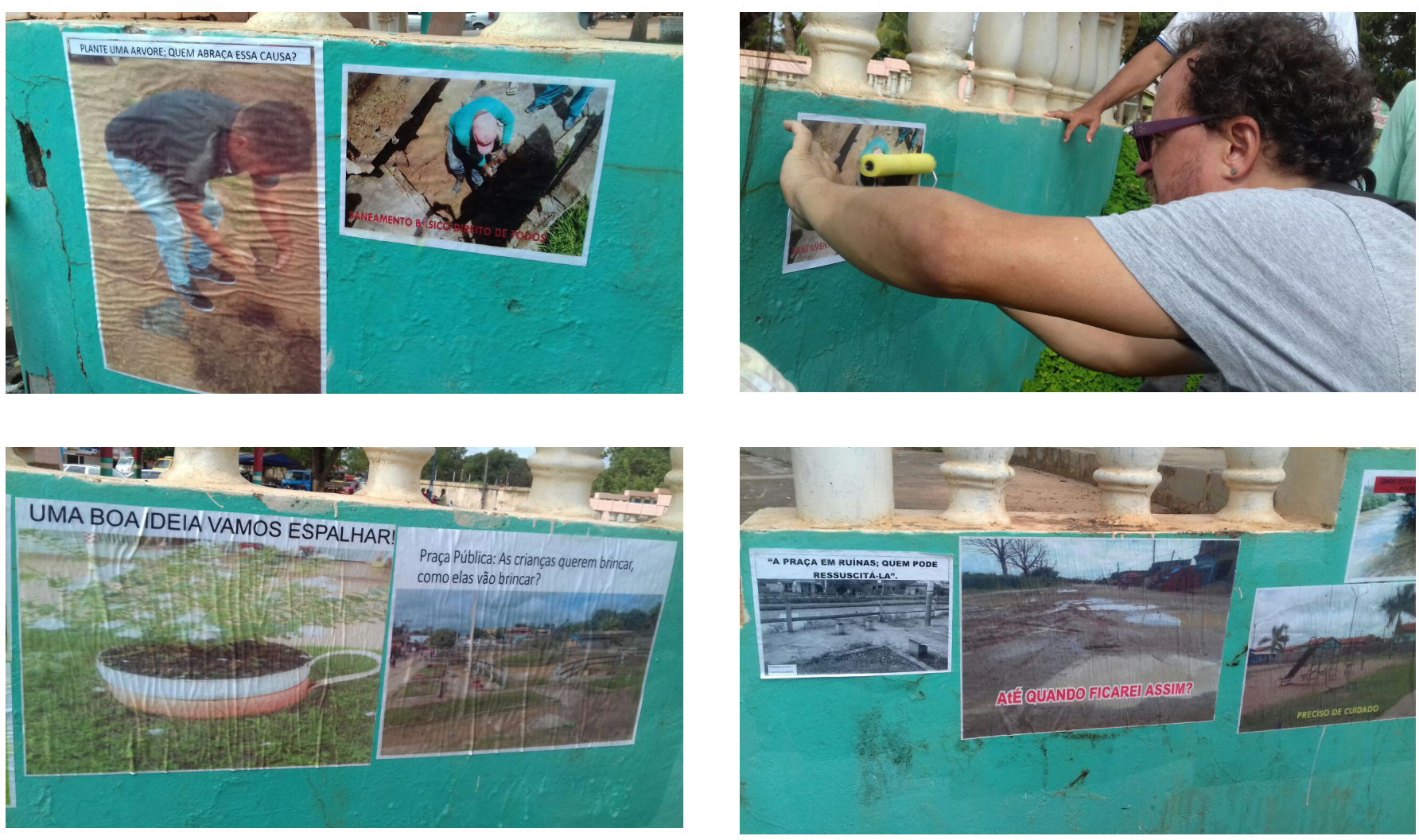

Fig. 5 - Sequência Intervenção [Fonte: Registros dos estudantes, 2017] 

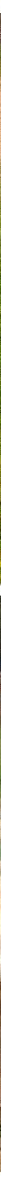

Fig. 6 - Sequência Intervenção [Fonte: Registros dos estudantes, 2017] 
DESLOCAMENTOS 2 - EDUCAÇÃO, ARTE E POLITICA EM AÇÃO NA FLORESTA [RESEX RIO IRIRI] E NA CIDADE [ALTAMIRA]

A segunda experiência que trazemos aqui foi vivenciada no âmbito do Projeto de Formação de Professores Extrativistas da Terra do Meio - Magistério ${ }^{4}$. Esse Projeto evidencia de modo muito radical o que estamos chamando de experiência de deslocamento, por vários motivos que não poderemos tratar aqui e por isso remetemos o leitor interessado a trabalhos mais especificos [especialmente PARENTE; LOPES; MILÉO, 2020]. Nosso relato incide em atividades desenvolvidas com os jovens extrativistas estudantes do Magistério na turma da Reserva Extrativista Rio Iriri, em duas ocasiões: nas aulas de Informática e Educação [em maio de 2019, na própria Resex] e na Instalação/exposição fotográfica Povos que gritam por inclusão [realizada na cidade de Altamira, em setembro de 2019].

O Magistério da Extrativista da Terra do Meio condensa, de forma bastante contumaz, a "gênese estética" partilhada pela arte e pela política, de que nos fala Rancière [2012], por se constituir medularmente como experiência educativa enraizada no cotidiano dos sujeitos implicados. Sua dimensão política é facilmente notável pelo sentido de afirmação de direitos que representou para as comunidades extrativistas quando conseguiram, por via da mobilização popular, que a Universidade Federal do Pará assumisse sua implementação, garantindo a dezenas de jovens extrativistas a elevação da escolaridade em nível do ensino fundamental e a conclusão do ensino médio, na modalidade Magistério.

Até um pouco antes da decretação das áreas de conservação, em meados dos anos 2000, as populações residentes na Terra do Meio não tinham sua existência reconhecida, vivendo em quase completa invisibilidade, excluídas de praticamente todos os direitos sociais afirmados na Constituição Federal de 1988; para se ter uma ideia desse processo de exclusão, basta saber que as primeiras escolas foram ali instaladas, e com muita precariedade, apenas em 2008.

No contexto da disciplina Informática e Educação, nosso objetivo principal foi refletir sobre o conceito de Tecnologias da Informação e Comunicação [TICs] em relação com o contexto local, problematizando usos e formas de apropriação, problematizando as desigualdades existentes nas formas de acesso a esses dispositivos. Nesse roteiro, começamos a fazer dentro de dispositivos de ensino e aprendizagem alguns experimentos para entender a realidade do lugar de maneira coletiva e, em grupo, criar possibilidades de reinvenção, de usos transgressores dos dispositivos estudados. Com isso, conseguimos explorar modelos "alternativos" 
para usos das TICs, utilizando os conceitos de remix, audiovisual, música e arte.

Mesmo estando nas reservas extrativistas, que são locais muito remotos, os jovens que participavam do projeto já faziam usos de tecnologias, inclusive com computadores e aparelhos celulares, mesmo não havendo luz elétrica, nem tampouco internet [eles se valem de geradores]. Sabemos que os usos das tecnologias estão presentes em processos de organização social e produção da vida, desde o arado, passando pelos instrumentos necessários à retirada do látex, até as TICs [PRETTO, 2011], com internet, celulares e câmeras presentes no cotidiano de jovens e adultos, com diversas maneiras inventivas.

Um dos pontos nodais da discussão foi como fazer uso dessas tecnologias para potencializar processos identitários e repensar a inserção social desses sujeitos e suas formas de vida, de luta e de afirmação de direitos. Assim, mobilizados pelo debate sobre temas que Ihes são caros, os estudantes se envolveram de tal modo na ação/reflexão coletiva e crítica sobre o contexto educativo usando as TICs, na perspectiva identitária, por meio de técnicas da remixagem do audiovisual, que chegaram a criar produtos primorosos, misturando imagens já realizadas e outras produzidas ali no momento, trazendo elementos do seu dia a dia, de forma inusitada, surpreendente e profundamente autoral.

No final, conseguimos criar, com produção de "baixo custo", seis videodocumentários produzidos e realizados pelos estudantes ${ }^{6}$, envolvendo temáticas que foram emergindo durante o processo de estudo, como a falta de postos de saúde para combater a malária, a falta de perspectiva de continuidade de estudos dentro das Resex, o transpor-

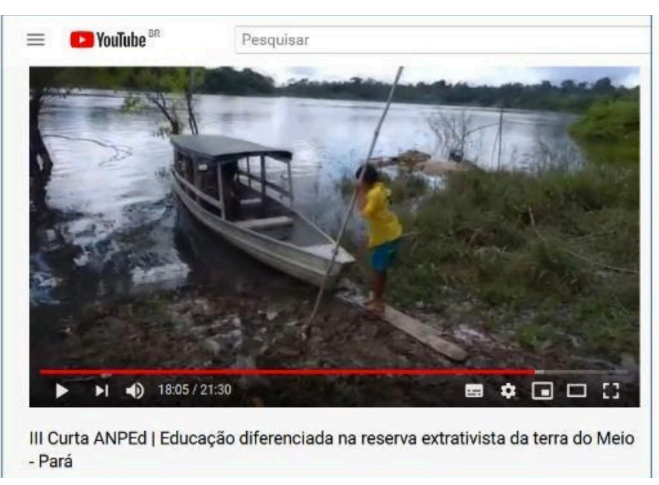

Fig. 7 - Sequência I/I Curta ANPEd / Educação diferenciada na reserva extrativista da terra do Meio - Pará [Fonte: imagens de internet ${ }^{5}$ ]

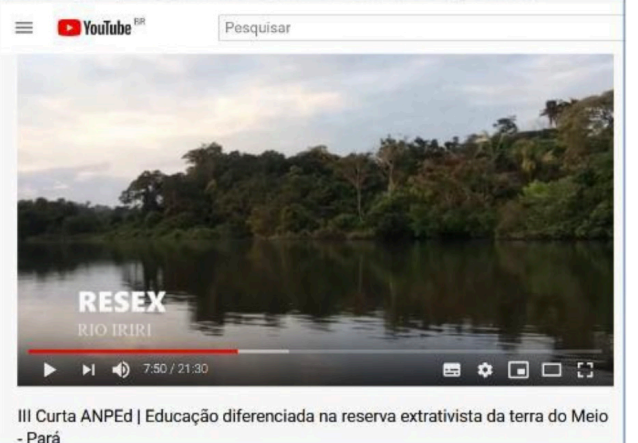

Revista Poiésis, Niterói, v. 22, n. 38, p. 82-105, jul./dez. 2021 [hitips://doi.org/10.22409/poiesis.v22i38.45642 
te escolar deficitário em barcos pouco seguros, os projetos de vida dos jovens, a questão do lazer e as condições de vida e de trabalho na região. Mesmo em pouco tempo, em torno de 10 dias, conseguimos trabalhar a potência dessa produção a partir do cotidiano desses jovens, cuja inventividade reverberou, para outros espaços, elementos de lutas e reinvindicações envolvendo a arte e a política, trazendo algo do comum para o audiovisual, uma singular experiência de nova partilha do sensível no interior da floresta amazônica. Esses vídeos trouxeram elementos sobre as possibilidades que já estavam sendo utilizadas e que foram incrementadas por uma mensagem clara no audiovisual, a ser passada para além das fronteiras da Resex. E o mais vital: superando a ideia de que esses jovens fossem apenas consumidores, para se tornarem autores desse processo.

Esses resultados, mas especialmente os processos que os geraram, corroboram a afirmação de Campbell [2015] a respeito da possibilidade de contrainformação dessas produções como apropriação dos meios e da produção da informação para deslegitimar o estado de poder das mídias "oficiais", pelo uso dos meios de comunicação; no caso presente, do audiovisual, mesmo que distante dos grandes centros urbanos. É como mais uma evidência dessa possibilidade, articulando arte e política de forma bastante interessante, que apresentamos a experiência a seguir, protagonizada pelos mesmos sujeitos e alguns novos parceiros.

A intervenção Povos que gritam por inclusão, que aconteceu no espaço urbano de Altamira, em setembro de 2019, foi uma espécie de desdobramento da experiência com audiovisual vivenciada na Resex, em maio do mesmo ano. Os experimentos com as TICs produziram vários sentidos sobre as imagens na região e, a partir desse trabalho, vários pontos foram sendo problematizados pelos estudantes extrativistas, como o próprio Projeto Magistério, o acesso à escola, a invisibilização da região e de seus modos de vida, as formas de trabalho e de lazer e vários outros elementos do cotidiano dessas populações.

Aproveitando da presença de alguns desses jovens na cidade, por ocasião de um evento de reivindicação de direitos em que eles usariam alguns dos produtos criados nas aulas em maio, propusemos uma ação artístico-política a partir da própria vivência no Projeto Magistério, por meio da criação e cocriação de produtos/obras de arte, em que fossem mostradas suas subjetividades, a visibilidade e invisibilidade envolvidas nos processos políticos, com suas especificidades, contradições, dissensos. 

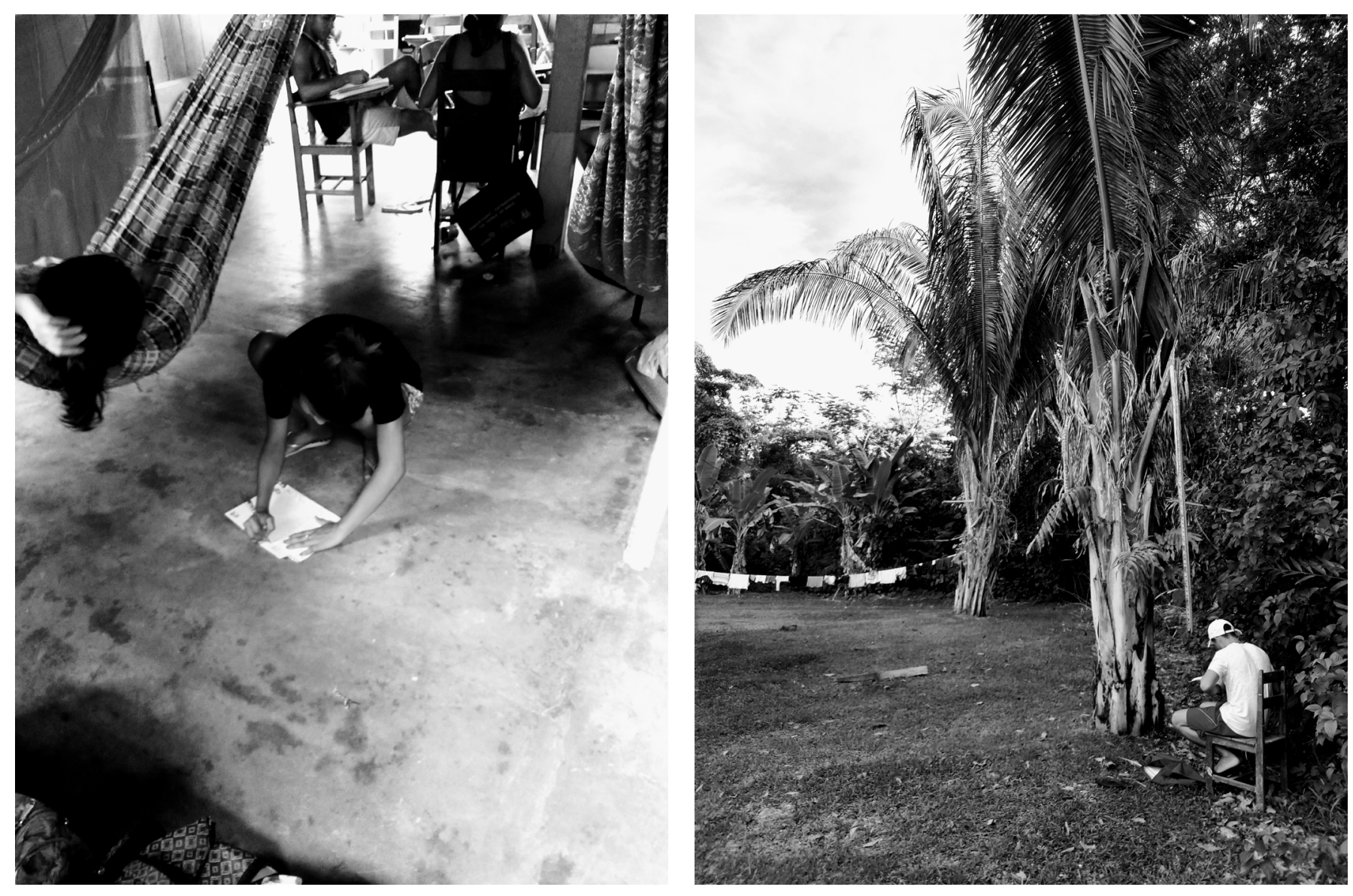

Fig. 8 - Sequência Resex [Fonte: Arquivo pessoal dos autores, 2019] 

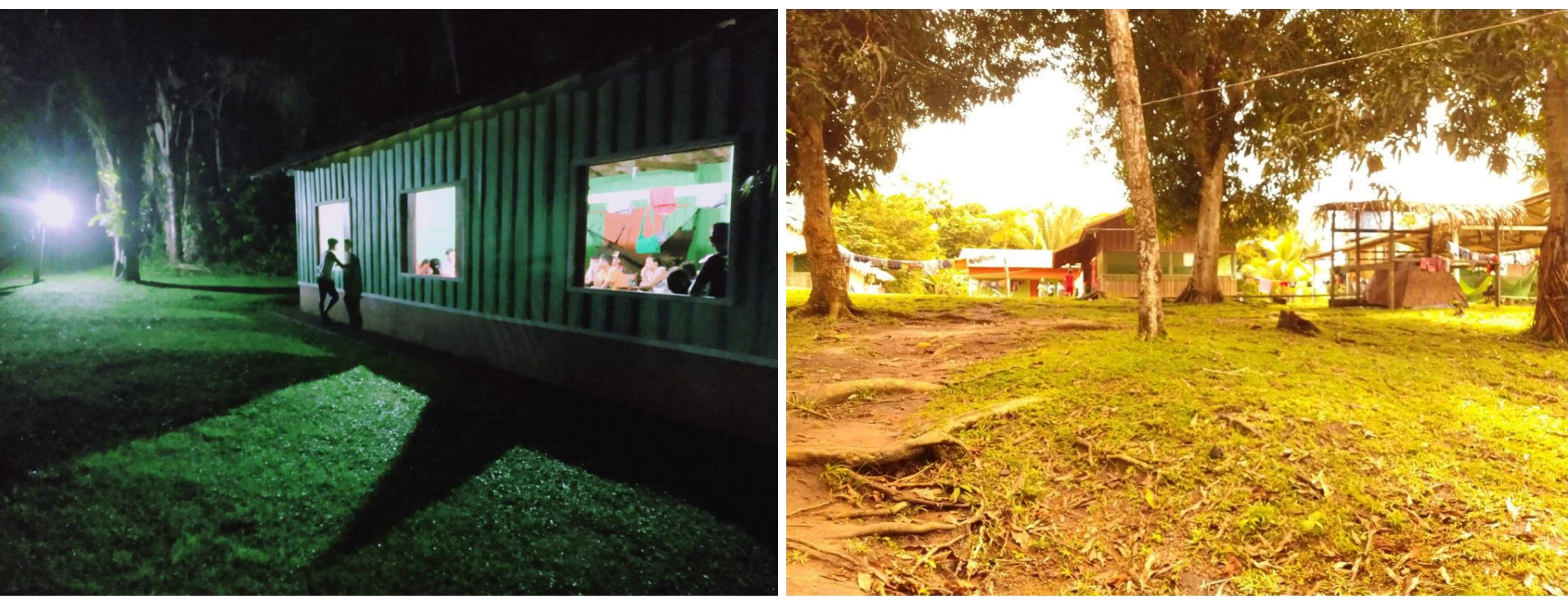

Fig. 9 - Sequência Resex [Fonte: Arquivo pessoal dos autores, 2019] 

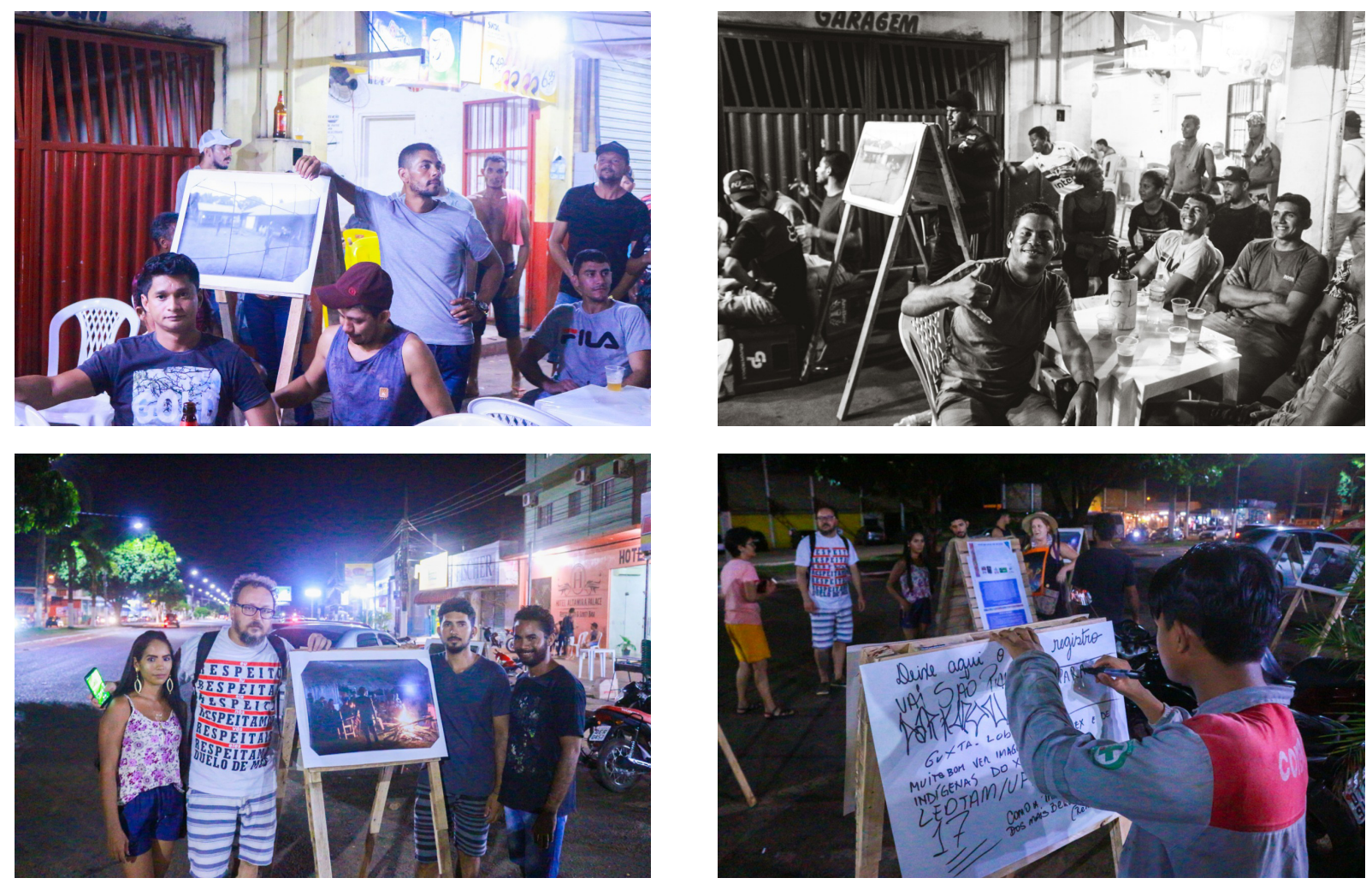

Fig. 10 - Sequência Intervenção Cidade. [Fonte: Arquivo pessoal dos autores, 2019] 

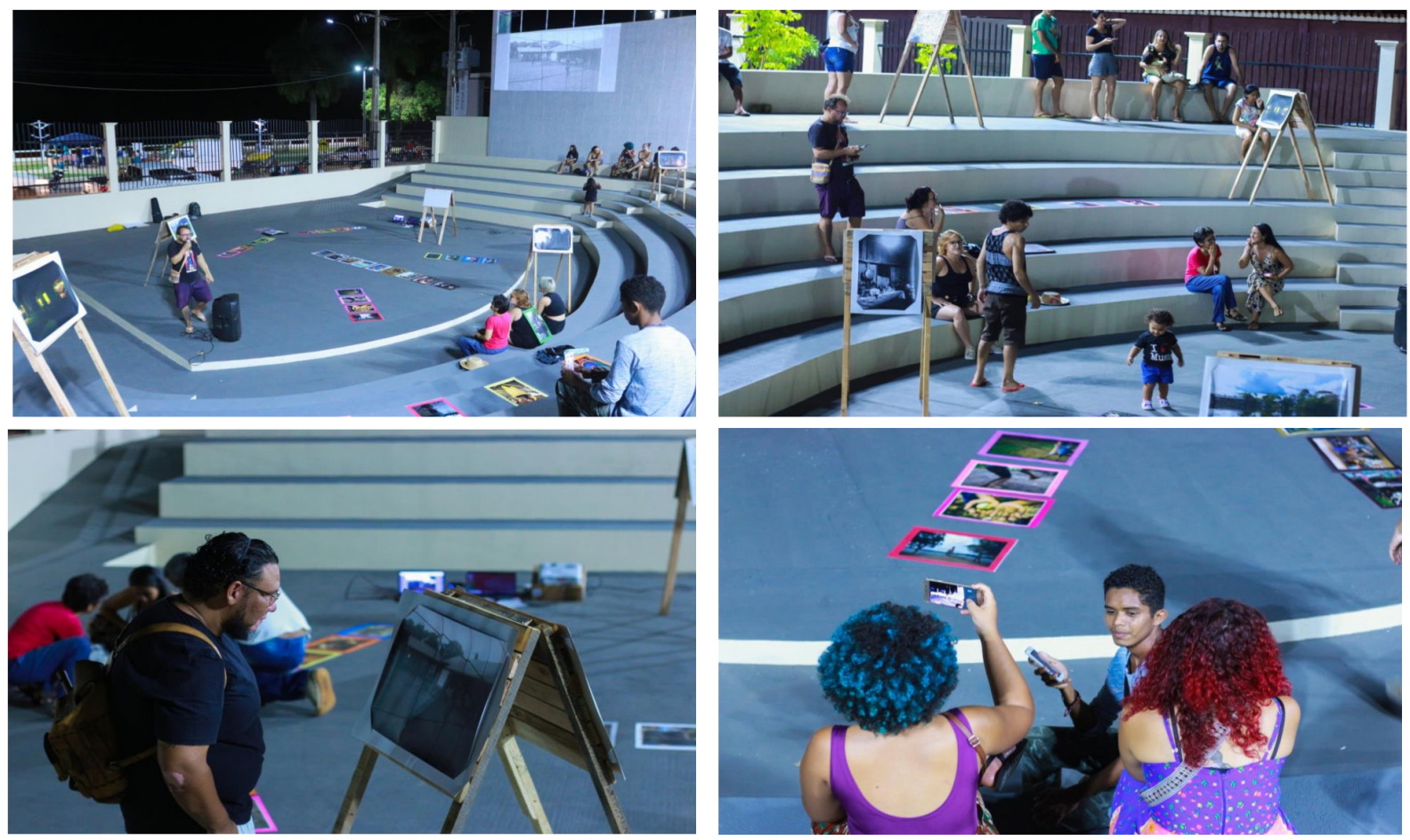

Fig. 11 - Sequência Intervenção Cidade [Fonte: Arquivo pessoal dos autores, 2019]

101 
Foram instalados cavaletes com as fotos. Houve execução de música local e também outras, executadas por outros artistas, como uma violinista que reinterpretou a canção Rosa de Hiroshima, trazendo singularidades como, por exemplo, referência à bomba de Hiroshima e ao processo de destruição da floresta amazônica. Esse remix trouxe novas indagações, um rompimento dos espaços/fluxos e novos olhares, subvertendo a lógica desses espaços.

A intervenção foi composta por imagens e apresentações de artistas interagindo na experiência vivida e pautando o poder inclusivo e transformador da educação em uma ambiente intercultural, trazendo para a cena pública novos atores e autores, num processo de diálogo e partilha do sensível, inclusive com a interação entre os habitantes da cidade em espaços inusitados para a educação escolar, como o bar e a praça.

\section{CONSIDERAÇÕES FINAIS}

As experiências em arte, educação e política aqui trazidas nos colocam a questão do compromisso epistêmico-existencial e tocam de muito perto aspectos implicados no nosso próprio fazer cotidiano, a que não costumamos prestar muita atenção, mas que concentram as possibilidades de concepção e elaboração do que Rancière chama "paisagem nova e inédita" com novas formas, estabelecendo novas conexões a partir de novos ritmos. Evidente que, quando embebidos na atividade, não estávamos percebendo essas questões de forma racional e direta. Mas, desde o momento em que estabelecemos o processo de intervenção a partir desse continuum, trazendo-o para a cidade e reconfigurando-o por meio das instalações, ficou evidente o desafio da nossa implicação no processo, suas singularidades e desdobramentos. O que está posto é como o público que vê e partilha esse novo sensível tornado comum pode ser tocado.

Uma das ideias foi trazer para a cidade fotografias sobre o tempo em que estávamos fazendo o trabalho na Resex, ocupando espaços diferentes como o bar e a praça, experimentando como os sujeitos poderiam trocar percepções, revisitar e cocriar novas perspectivas. Nessas intervenções, estiveram presentes estudantes das reservas extrativistas, movimentos sociais que trabalham com povos indígenas e também moradores da cidade que não conheciam ou não conhecem as reservas extrativistas, mas têm sobre elas e seus habitantes pré-conceitos e julgamentos de valor.

Assim como a experiência em Uruará, essas vivências mostraram que o fazer artístico como ato político de projeção dos sujeitos na esfera pública 
é uma forma de produção de saber, que responde

a necessidades humanas mediante a construção de objetos de conhecimento, os quais, juntamente com as relações sociais, políticas e econômicas, compõem um conjunto de manifestações características de uma determinada cultura. Nesse contexto, o fazer artístico, como prática estética mas também como mecanismo de ruptura de uma certa ordem estabelecida, passa também a ser peça fundamental nos movimentos políticos, pois os coletivos que experimentam esse novo sensível passam a ter uma atitude reflexiva e ativa diante dos problemas sociais, o que pode contribuir para ressignificar a vida pela construção e partilha de um novo comum. <

\section{NOTAS}

1 VELOSO, Caetano. Terra. Rio de Janeiro: Phillips, 1978.

2 Disponível no site do artista: http:/ / www.ederoliveira.net/ intervencoes\#7. Acesso em julho de 2020.

3 O Programa Nacional de Formação de Professores da Educação Básica [Parfor] é uma ação da CAPES que visa induzir e fomentar a oferta de educação superior, gratuita e de qualidade, para profissionais do magistério que estejam no exercício da docência na rede pública de educação básica e que não possuem a formação específica na área em que atuam.

4 Este Projeto foi elaborado de forma colaborativa com as próprias comunidades demandantes e realizado por meio de parceria interinstitucional entre a Faculdade de Etnodiversidade da Universidade Federal do Pará [UFPA] e a Escola de Aplicação [EA/UFPA], com o apoio do Ministério da Educação [MEC] e das Associações de Moradores da áreas envolvidas [AMORA, AMORERI, AMOMEX, e AERIM], com início em dezembro de 2015 e término em dezembro de 2019. Seu principal objetivo foi a formação de jovens comunitários para atuar nas escolas das três Resex de Altamira [Riozinho do Anfrísio, Rio Iriri e Xingu] e adjacências, como professores dos anos iniciais. 5 Disponivel em https://www.youtube.com/watch? v=Z4Rkux-7ZA. Acesso em 26/10/2020.

6 Uma dessas produções foi enviada e aprovada para o Festival de Curtas da Associação Nacional de Pós-Graduação em Educação. 
ALVES, Nilda. Sobre movimentos das pesquisas nos/dos/com os cotidianos. TEIAS. Rio de Janeiro, ano 4, n. 7-8, jan./dez. 2003.

ALVES, Nilda. Tecer conhecimento em rede. In ALVES Nilda; GARCIA, Regina Leite [Orgs.]. O sentido da escola. $5^{a}$ edição. Coleção Pedagogias em Ação. Petrópolis: DP et Alii, 2008.

ARDOINO, Jacques. Abordagem multirreferencial [plural] das situações educativas e formativas. In BARBOSA, Joaquim Gonçalves [Coord.]. Multirreferencialidade nas ciências e na educação. São Carlos: Editora da UFSCar, 1998. p. 24-41.

BONDÍA, Jorge Larrosa. Notas sobre a experiência e o saber de experiência. Revista Brasileira de Educação. n.19, [online], 2002, p. 20-28. ISSN 1413-2478.

CAMPBELL, Brígida. Arte para uma cidade sensível. São Paulo: Editora Invisíveis Produções, 2015.

CERTEAU, Michel de. A invenção do cotidiano: artes do fazer. 16ª edição. Petrópolis: Vozes, 2009.

CORDEIRO, L. Z.; LOPES, R.. Territórios do saber x territórios do viver formação docente em hetero-espaços no interior da amazônia. Pesquisa e Debate Em Educação, v. 25, Juiz de Fora, p. 299, 2020.

DUARTE JR., João Francisco. O sentido dos sentidos: a educação [do] sensível. 2000. Tese [Doutorado em Educação] - Universidade Estadual de Campinas, Campinas, 2000.

PARENTE, Francilene de Aguiar; LOPES, Raquel da Silva; MILÉO, Irlanda do Socorro. Pedagogia da Alternância na Formação de Professores Extrativistas: uma experiência na Terra do Meio, em Altamira/PA. Humanidades \& Inovação, v. 7, n. 12, Palmas, 2020, p. 63-77.

PRETTO, Nelson de Lucca. O desafio de educar na era digital: educações. Revista Portuguesa de Educação, 2011, v. 24, n. 1, Braga, Universidade do Minho, p. 95-118, 2011. 
RANCIÈRE, Jacques. A partilha do sensível: estética e política. São Paulo: Editora 34, 2005.

RANCIĖRE, Jacques. O espectador emancipado. São Paulo: Editora WMF Martins Fontes, 2012.

SANTOS, Edméa; WEBER, Aline. Diários on-line, cibercultura e pesquisa-formação multirreferencial. In LIMA, Maria do Socorro Lucena; CAVALCANTE, Maria Marina Dias; SALES, José Albio Moreira de; FARIAS, Isabel Maria Sabino de [org.]. Didática e Prática de Ensino na relação com a Escola. Fortaleza: Editora da Universidade Estadual do Ceará, 2015. Livro 1, p. 1775-1786.

Disponível em: http://uece.br/endipe2014/ebooks/livro1/205-\%20DI\%C3\%81RIOS\%20ONLINE,\%20CIBERCULTURA\%20E\%20PESQUISA-FORMA\%C3\%87\%C3\%830\%20MULTIRREFERENCIAL. pdf. Acesso em 25/10/2020. 